\title{
The 1000 Canadian Faces of Lupus: Determinants of Disease Outcome in a Large Multiethnic Cohort
}

\author{
CHRISTINE A. PESCHKEN, STEVEN J. KATZ, EARL SILVERMAN, JANET E. POPE, PAUL R. FORTIN, \\ CHRISTIAN PINEAU, C. DOUGLAS SMITH, HECTOR O. ARBILLAGA, DAFNA D. GLADMAN, \\ MURRAY UROWITZ, MICHEL ZUMMER, ANN CLARKE, SASHA BERNATSKY, MARIE HUDSON, \\ and the Canadian Network for Improved Outcomes in Systemic Lupus Erythematosus (CaNIOS)
}

\begin{abstract}
Objective. To describe disease expression and damage accrual in systemic lupus erythematosus (SLE), and determine the influence of ethnicity and socioeconomic factors on damage accrual in a large multiethnic Canadian cohort.

Methods. Adults with SLE were enrolled in a multicenter cohort. Data on sociodemographic factors, diagnostic criteria, disease activity, autoantibodies, treatment, and damage were collected using standardized tools, and results were compared across ethnic groups. We analyzed baseline data, testing for differences in sociodemographic and clinical factors, between the different ethnic groups, in univariate analyses; significant variables from univariate analyses were included in multivariate regression models examining for differences between ethnic groups, related to damage scores.

Results. We studied 1416 patients, including 826 Caucasians, 249 Asians, 122 Afro-Caribbeans, and 73 Aboriginals. Although the overall number of American College of Rheumatology criteria in different ethnic groups was similar, there were differences in individual manifestations and autoantibody profiles. Asian and Afro-Caribbean patients had more frequent renal involvement and more exposure to immunosuppressives. Aboriginal patients had high frequencies of antiphospholipid antibodies and high rates of comorbidity, but disease manifestations similar to Caucasians. Asian patients had the youngest age at onset and the lowest damage scores. Aboriginals had the least education and lowest incomes. The final regression model $\left(\mathrm{R}^{2}=0.27\right)$ for higher damage score included older age, longer disease duration, low income, prednisone treatment, higher disease activity, and cyclophosphamide treatment.

Conclusion. There are differences in lupus phenotypes between ethnic populations. Although ethnicity was not found to be a significant independent predictor of damage accrual, low income was. (First Release April 15 2009; J Rheumatol 2009;36:1200-8; doi:10.3899/jrheum.080912)
\end{abstract}

Key Indexing Terms:

SYSTEMIC LUPUS ERYTHEMATOSUS

INDIANS NORTH AMERICAN

ETHNIC DISPARITY ASIAN-CANADIANS

Systemic lupus erythematosus (SLE) is a multisystem chronic disease whose manifestations and outcome are known to vary among ethnic groups. Higher prevalence rates have been described in a number of ethnicities, including African Americans ${ }^{1-7}$, Asians ${ }^{5,8-10}$, and Aboriginals (Native Americans) ${ }^{11-13}$. Clinical manifestations, course, and outcome of SLE also differ between ethnic

From the Department of Medicine, University of Manitoba, Winnipeg, Manitoba, Canada.

Supported by a grant from The Arthritis Society National Office, Toronto, Ontario, Canada.

C.A. Peschken, MD, MSc, Assistant Professor, Departments of Medicine and Community Health Sciences, University of Manitoba, Winnipeg, Manitoba; S.J. Katz, MD, BSc, Resident in Rheumatology, Department of Medicine, University of Alberta, Edmonton, Alberta; E.D. Silverman, MD, Professor of Medicine, Department of Pediatrics, University of Toronto, and Hospital for Sick Children, Toronto; J.E. Pope, MD, MPH, Associate Professor of Medicine, Department of Medicine, University of Western Ontario, London; P.R. Fortin, MD, MPH, Professor of Medicine, Department of Medicine, University of Toronto, Toronto, Ontario C. Pineau, MD, Assistant Professor, Department of Medicine, McGill University Hospital, Montreal, Quebec; C.D. Smith, MD, Associate groups ${ }^{8,12-18}$, with more severe disease and worse outcomes described for some groups, particularly African American and Hispanic patients with lupus ${ }^{14,19-23}$. Although there are few data to date, studies utilizing review of medical records suggest that SLE in Aboriginals tends to be more severe and outcomes appear to be worse $\mathrm{e}^{11-13}$.

Socioeconomic status is an important predictor of poor 
outcomes in SLE, with multiple studies linking poverty and lack of education with higher rates of mortality and damage $^{24-26}$. Canada has a universal public healthcare system, providing equal access to the same healthcare system across all ethnic groups and income levels; however, utilization of healthcare resources as well as other health-related behaviors may well differ.

The 1000 Canadian Faces of Lupus project is a multicenter, prospective study of the Canadian lupus population. Its objectives were to determine the influence of ethnicity and socioeconomic factors on disease activity, organ involvement, and disease outcomes. This study is particularly important as ethnic minorities are growing at a faster rate in Canada compared to the rest of the population. There is a marked paucity of North American data on lupus in Asians and Aboriginals (Native Americans), 2 populations that are growing at twice the rate of the general Canadian popula$\operatorname{tion}^{27,28}$. In this article, we present the baseline description of our multiethnic cohort, comparing patients of different ethnic backgrounds, in the setting of a universal public healthcare system.

\section{MATERIALS AND METHODS}

Patients. Patients were enrolled at 14 sites across Canada, 10 adult rheumatology clinics and 4 pediatric rheumatology clinics. Our study focuses on the adult rheumatology patients. Patients were eligible if they were identified by the site investigator(s) as having a clinical diagnosis of SLE. A clinical diagnosis of SLE, rather than the requirement to meet the American College of Rheumatology (ACR) criteria for $\mathrm{SLE}^{29}$, was allowed. However, the vast majority $(1380 / 1416)$ of patients met $\geq 4$ criteria at the time of enrollment. Both incident and prevalent cases were included. The number of patients at participating sites who declined enrollment was $<5 \%$. Ethics approval was obtained at each participating site.

Study variables. At the baseline visit, all available medical records were reviewed by the site investigators, and clinical data were abstracted and entered onto a comprehensive form. Clinical manifestations of lupus, including those forming the ACR criteria and those included in the revised Systemic Lupus Activity Measure (SLAM-R) $)^{30,31}$ and the revised SLE Disease Activity Index (SLEDAI-2K) ${ }^{32,33}$, as well as the date of first occurrence of each manifestation were noted where available. In addition, autoantibody status was recorded for anti-dsDNA (DNA), anti-Sm (Sm), anti-RNP (RNP), anti-La (La), anti-Ro (Ro), and antiphospholipid antibodies (aPL; includes anticardiolipin and lupus anticoagulant). "Ever positive" was collected from the medical record, and blood was collected at the baseline visit and annually to determine current status for antinuclear antibodies (ANA), DNA, Sm, RNP, La, Ro, and aPL. (An individual was considered aPL-positive if either anticardiolipin or lupus anticoagulant was present). Disease activity was measured at baseline and annually using the SLAM-R and the SLEDAI-2K validated lupus activity scales ${ }^{30-33}$. The SLAM-R also includes a $10-\mathrm{cm}$ visual analog scale (VAS) of physician-assessed global disease activity. Patients also filled out the Self-Assessed Lupus Activity Questionnaire (SLAQ) ${ }^{34}$, a validated self-reported measure of disease activity, at baseline and each followup visit, which includes a VAS for global disease activity and fatigue. Current and past medication use were recorded and updated at each visit, and patients filled out a generic health status measure, the Medical Outcomes Study Short Form-36 ${ }^{35}$. Components of the Systemic Lupus International Collaborating Clinics/ACR Damage Index (SDI) ${ }^{36,37}$ were abstracted from the medical record, and reviewed with the patients during the interview, and updated annually. Components of the Charlson Comorbidity Index (CCI $)^{38}$, a validated measure of comorbidity, were collected and updated in a similar fashion.

Detailed sociodemographic data were collected including age, sex, highest education achieved, total household income, and self-reported ethnicity based on the format and categories used by Statistics Canada ${ }^{39}$. For the purposes of our analysis, patients were categorized according to the main self-chosen ethnic category; however, patients were allowed multiple choices, and detailed information on parents' and grandparents' ethnic background as well as country of origin was also collected. Patients were also asked about smoking habits, physical activity, alcohol use, and perceptions of healthcare access. Questions included availability of a primary care physician, distance from healthcare providers (primary and specialist), and perceptions of difficulty in accessing care providers and medications.

Statistical analyses. Analyses were performed using SPSS 15.0 statistical software (SPSS Inc., Chicago, IL, USA). Ninety percent of enrolled patients belonged to 1 of 4 ethnic groups, therefore the analysis focused on the clinical and sociodemographic differences among these 4 groups. Descriptive analyses of the differences among these 4 ethnic groups were performed with the chi-squared distribution for categorical variables and with analysis of variance for continuous variables. Spearman's correlation coefficients were computed for associations between continuous socio-demographic variables and disease activity and SDI scores. Multivariate linear regression analysis was performed to ascertain independent predictors of damage. Those variables whose association was found to attain a level of significance of $\mathrm{p} \leq 0.01$ in univariate analysis were retained in the multivariate analysis. Stepwise, forward, and backward multivariate analyses yielded identical results.

\section{RESULTS}

Between July 2005 and September 2007, 1537 patients were enrolled into the study cohort. One hundred twenty-one were pediatric patients; their data will be presented in a separate article. Of the 1416 adults, 826 patients were Caucasian (62\%), 249 Asian (19\%), 122 Afro-Caribbean (9\%), and 73 Aboriginal (5\%). Seventy-five patients were excluded from our analysis as their ethnicity was not reported. A further 71 participants were also excluded as their ethnicity was other than the 4 main groups. Demographic data are presented in Table 1. The average age at the baseline visit was $45 \pm 15$ years, with an average age of onset of $32 \pm 14$ years. Age at disease onset was highest in Caucasians and Aboriginals at 33 and 34 years, respectively, followed by Afro-Caribbeans (30 yrs), and Asian patients the youngest at 25 years ( $<<$ 0.001; Table 1). Ninety percent of all patients were women; however, there were significantly more Asian men at $17 \%$, and only $4 \%$ of Afro-Caribbean patients were men ( $\mathrm{p}=0.001$ across groups). Mean disease duration was $12 \pm 10$ years, and was longest in the Caucasian group at 14 years, and shortest in the Aboriginal patients at 7 years ( $p<0.001)$. High school completion was much lower among the Aboriginal patients, at $55 \%$, in contrast to $85 \%-93 \%$ in the other 3 groups $(\mathrm{p}<0.001)$. Aboriginals and Afro-Caribbeans were twice as likely to report total annual household incomes $<\$ 15,000$ compared to Caucasians and Asians (23\% and $19 \%$ vs $11 \%$ and $9 \%$; $\mathrm{p}=0.004)$; and less than one-third of Aboriginals and Afro-Caribbeans reported incomes in the highest income

Personal non-commercial use only. The Journal of Rheumatology Copyright $\odot$ 2009. All rights reserved. 
Table 1. Selected demographic and clinical characteristics of the cohort.

\begin{tabular}{|c|c|c|c|c|c|}
\hline Variable & $\begin{array}{c}\text { Caucasian, } \\
\mathrm{n}=826\end{array}$ & $\begin{array}{l}\text { Aboriginal, } \\
\mathrm{n}=73\end{array}$ & $\begin{array}{l}\text { Afro-Caribbean, } \\
\mathrm{n}=122\end{array}$ & $\begin{array}{l}\text { Asian, } \\
\mathrm{n}=249\end{array}$ & $\mathrm{p}$ \\
\hline Sex, $\%$ female & 91 & 89 & 96 & 83 & 0.001 \\
\hline Disease duration, mean yrs \pm SD & $14 \pm 10.6$ & $7 \pm 6.7$ & $10 \pm 8.9$ & $11 \pm 7.8$ & $<0.001$ \\
\hline Age, mean yrs $\pm \mathrm{SD}$ & $47 \pm 14.4$ & $40 \pm 11.7$ & $40 \pm 13.6$ & $35 \pm 12.8$ & $<0.001$ \\
\hline High school graduates, $\%$ & 85 & 55 & 91 & 93 & $<0.001$ \\
\hline$\geq \$ 15-25,000 \mathrm{Cdn}$ & 13 & 16 & 26 & 15 & \\
\hline$>\$ 25-50,000 \mathrm{Cdn}$ & 23 & 30 & 28 & 23 & \\
\hline$>\$ 50,000 \mathrm{Cdn}$ & 53 & 32 & 28 & 53 & \\
\hline ACR criteria met, mean no. \pm SD & $6.0 \pm 1.7$ & $5.7 \pm 1.7$ & $5.8 \pm 1.6$ & $6.2+1.7$ & NS \\
\hline Charlson Comorbidity Index & 1.5 & 1.7 & 1.3 & 1.2 & 0.05 \\
\hline No Damage: SLICC Index $=\%$ & 42 & 39 & 35 & 59 & $<0.001$ \\
\hline
\end{tabular}

ACR: American College of Rheumatology; SLICC: Systemic Lupus International Collaborating Clinics. NS: nonsignificant.

bracket (> $\$ 50,000 / y r)$ compared to over half of Asian and Caucasian patients (Table 1).

The number of ACR criteria met did not differ among the 4 ethnic groups; however, the frequency of fulfilling individual ACR criteria did vary significantly (Figure 1). Asians and Afro-Caribbeans had more frequent renal involvement, at $59 \%$ and $56 \%$, compared to Caucasians $(40 \%)$ and Aboriginals $(39 \%)(\mathrm{p}<0.001)$. Asians had the lowest frequency of arthritis ( $64 \%$ vs $82 \%$ for total group) $(\mathrm{p}<0.001)$ and serositis (23\% vs $34 \%$ for total group) ( $\mathrm{p}=0.002)$, while Caucasians had more frequent mucocutaneous fea- tures (mucosal ulcerations, photosensitivity, and malar rashes; $87 \%$ vs $78 \%$ for total group) ( $p<0.001)$ except for discoid rashes, which were most common in Afro-Caribbeans ( $30 \%$ vs $11 \%$ for total group) ( $p<0.001)$. There were also differences in less typical manifestations of lupus. Asians and Aboriginals were more likely to experience fever (17\% and $24 \%$, respectively, vs $10 \%$ in Caucasians, and $9 \%$ in Afro-Caribbeans) $(\mathrm{p}<0.001)$ and weight loss as part of their lupus $(22 \%$ and $17 \%$, respectively, vs $11 \%$ in Caucasians and Afro-Caribbeans) $(\mathrm{p}=0.018)$, and Aboriginals had more frequent non-malar lupus-related rashes $(20 \%$ vs $9 \%$ for

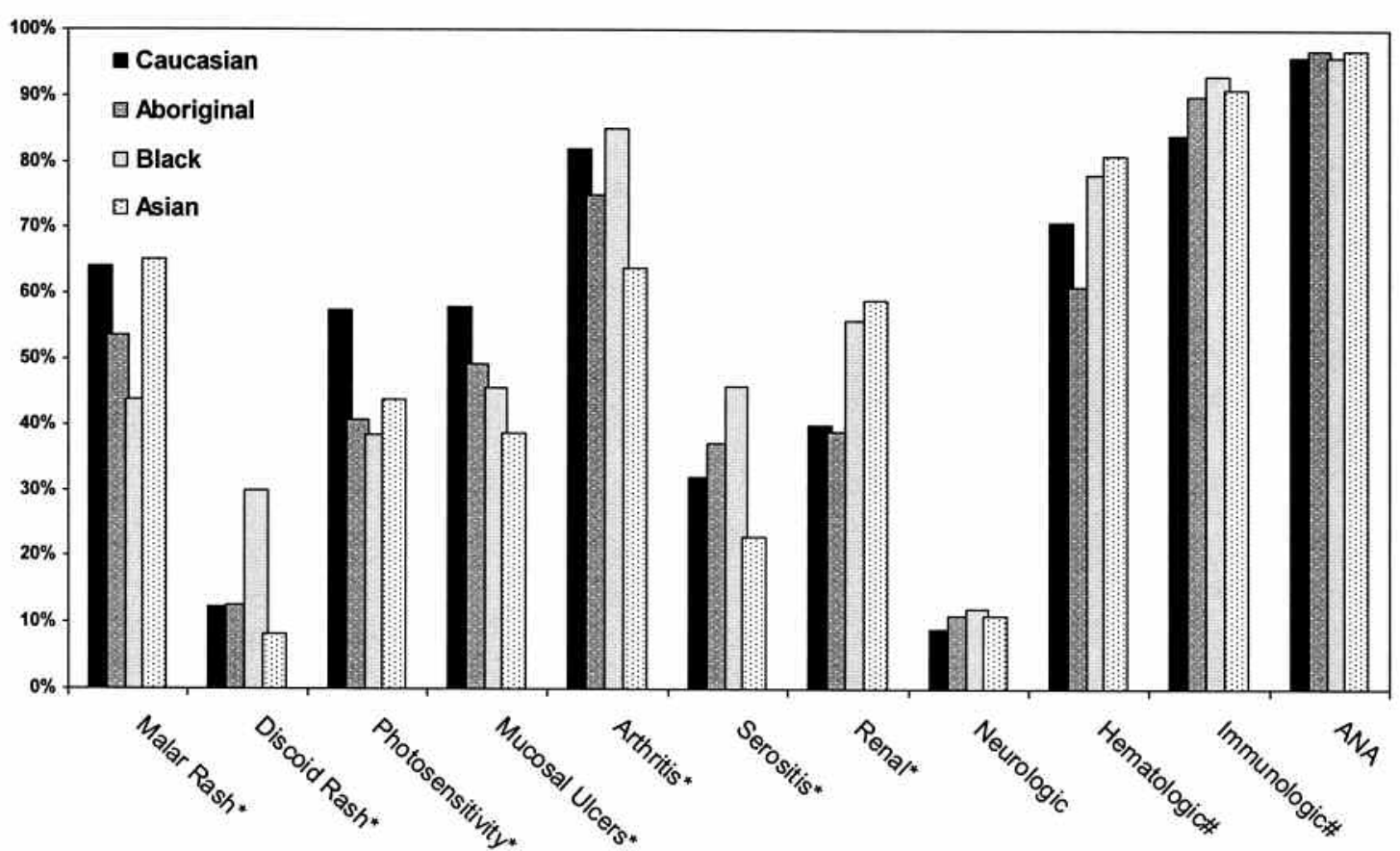

Figure 1. Proportion of patients in each ethnic group meeting individual ACR criteria for SLE at the baseline study visit. Chisquared distribution, ${ }^{*} \mathrm{p}<0.001 ;{ }^{\#} \mathrm{p}<0.01$. 
total group) $(\mathrm{p}=0.005)$, cutaneous vasculitis $(15 \%$ vs $6 \%$ for total group) $(\mathrm{p}=0.006)$, and mononeuritis multiplex $(6 \%$ vs $1 \%$ for total group) ( $\mathrm{p}=0.011)$.

Serologic differences are shown in Figure 2. DNA antibodies were more frequent in all 3 non-Caucasian ethnic groups at $68 \%$ in Aboriginals, 64\% in Afro-Caribbeans, and $73 \%$ in Asians, compared to $55 \%$ in Caucasians ( $p<0.001$ ). $\mathrm{Sm}$ and RNP were most common in Afro-Caribbean patients at $55 \%$ and $48 \%$, compared to $31 \%$ and $17 \%, 27 \%$ and $25 \%$, and $39 \%$ and $23 \%$ in Caucasians, Aboriginals, and Asians, respectively ( $\mathrm{p}<0.001$ for both $\mathrm{Sm}$ and $\mathrm{RNP}$ ). There were no significant differences in the frequency of Ro and La. Fifty percent of Aboriginal and Asian patients were positive for anticardiolipin antibodies, compared to one-third of Caucasian and Afro-Caribbean patients $(\mathrm{p}=0.05)$. The lupus anticoagulant was also more frequent in Aboriginal patients at $28 \%$, compared to $18 \%$ in Caucasians, $11 \%$ in Afro-Caribbeans, and 10\% in Asians ( $\mathrm{p}=0.004)$.

Disease activity as measured by SLEDAI-2K showed no difference among the 4 ethnic groups (data not shown), with an overall mean score of 4.8. SLAM-R scores were significantly lower in Asian patients at 4.10, compared to 6.36 in Caucasians, 7.11 in Aboriginals, and 5.43 in Afro-Caribbeans $(\mathrm{p}<0.001)$. When SLAM-R and SLE-DAI-2K scores were divided into quartiles, there were no differences in the proportion of patients from the 4 ethnic groups in the 4 quartiles of the SLEDAI-2K score (data not shown). However, there was a higher proportion of Aboriginal patients with SLAM scores in the highest quar- tile at $35 \%$, compared to $10 \%$ in Asians, $16 \%$ in Afro-Caribbeans, and $23 \%$ in Caucasians; and the smallest proportion of Aboriginal patients with SLAM scores in the lowest quartile at $12 \%$, compared to $57 \%$ in Asians, $47 \%$ in Afro-Caribbeans, and $31 \%$ in Caucasians ( $p<0.001$ ). Physician global disease activity VAS scores did not differ among ethnic groups (data not shown), with an overall mean of $1.4 \mathrm{~cm}$, but patient global rating of disease activity was significantly lower in Asians at 2.8/10, compared to Caucasians (3.9), Aboriginals (4.1), and Afro-Caribbeans (3.8) $(\mathrm{p}<0.001)$.

Treatment differences. There were no differences in the use of antimalarials, with approximately two-thirds of all patients taking antimalarials at the time of the baseline visit, and about $16 \%$ who had never taken antimalarials (Table 2). However, significantly more Asians and Afro-Caribbeans were being treated with prednisone $(65 \%$ and $67 \%$, respectively) or mycophenolate mofetil (16\% and 13\%, respectively) at the baseline visit compared to Caucasians and Aboriginals ( $\mathrm{p}<0.001$ for all comparisons). Past treatment with prednisone and mycophenolate mofetil was also higher in Asians and Afro-Caribbeans (Table 2). All non-Caucasian ethnic groups were significantly more likely to have received cyclophosphamide in the past ( $\mathrm{p}=0.002$; Table 2). Current use of cyclophosphamide was low, at about $2 \%$ of patients overall.

Asians were least likely to have accumulated any damage, with $59 \%$ having an SDI score of zero $(\mathrm{p}<0.001$; Table 1). Asians also had the lowest mean SDI scores, at 0.95 ,

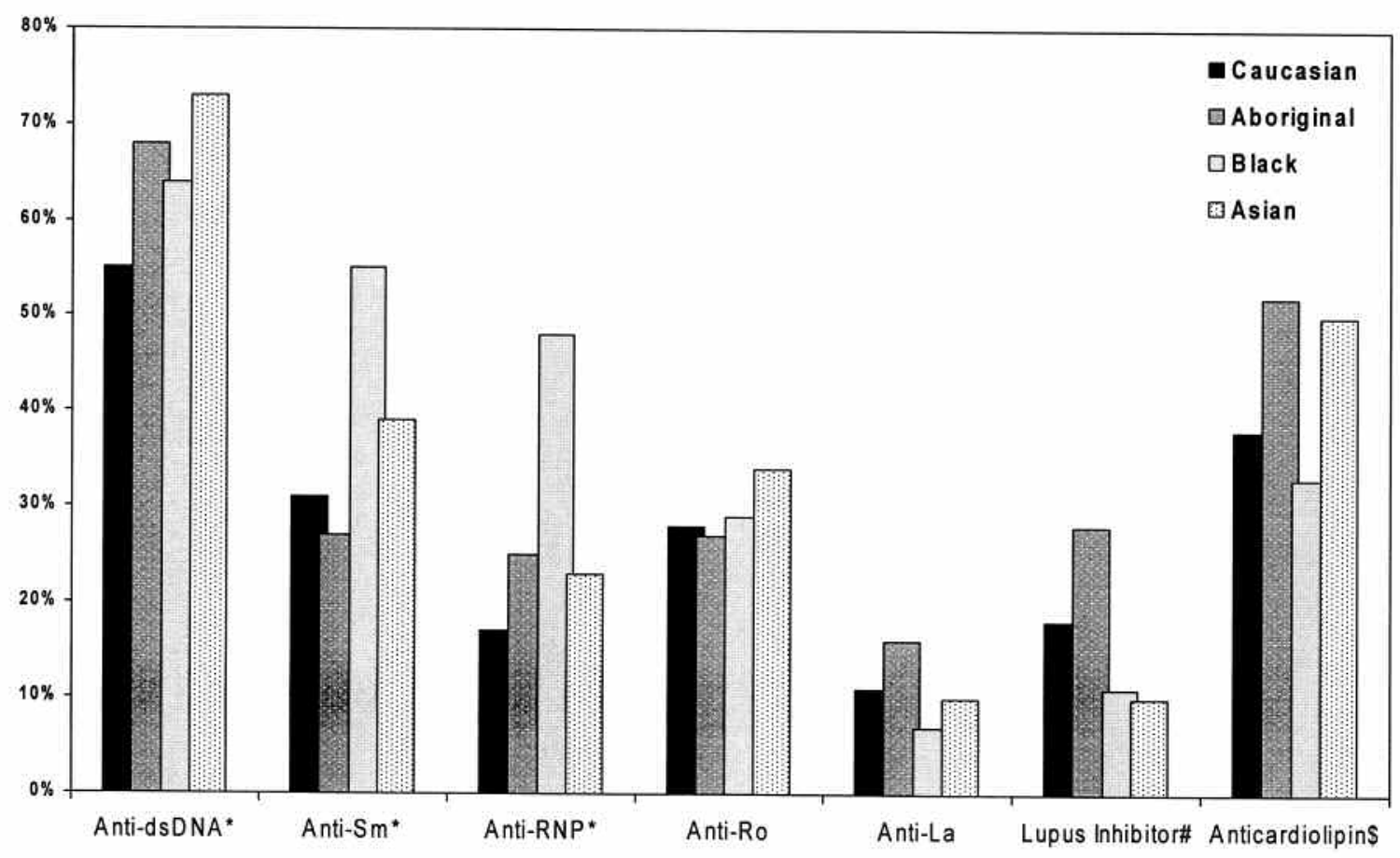

Figure 2. Proportion of patients in each ethnic group ever positive for autoantibodies. Chi-squared distribution, *p $<0.001$; $\mathrm{p}<$ $0.001 ;{ }_{\mathrm{p}}<0.05$.

Personal non-commercial use only. The Journal of Rheumatology Copyright $\odot$ 2009. All rights reserved. 
Table 2. Treatment.

\begin{tabular}{|c|c|c|c|c|c|}
\hline Variable & $\begin{array}{c}\text { Caucasian, } \\
\mathrm{n}=826\end{array}$ & $\begin{array}{c}\text { Aboriginal, } \\
\mathrm{n}=73\end{array}$ & $\begin{array}{l}\text { Afro-Caribbean, } \\
\quad \mathrm{n}=122\end{array}$ & $\begin{array}{l}\text { Asian, } \\
\mathrm{n}=249\end{array}$ & $\mathrm{p}$ \\
\hline \multicolumn{6}{|c|}{ Antimalarial, \% (n) } \\
\hline Baseline visit & $68(562)$ & $66(48)$ & $65(79)$ & 72 (179) & NS \\
\hline Never treated & $17(140)$ & $21(15)$ & $13(16)$ & $16(40)$ & NS \\
\hline \multicolumn{6}{|c|}{ Prednisone, \% (n) } \\
\hline Baseline visit & $42(345)$ & $38(28)$ & $67(82)$ & $65(161)$ & $<0.001$ \\
\hline Past use & $52(432)$ & $37(27)$ & $66(81)$ & 64 (159) & $<0.001$ \\
\hline \multicolumn{6}{|c|}{ Cyclophosphamide, \% (n) } \\
\hline Baseline visit & $2(14)$ & $4(12)$ & $2(3)$ & $2(5)$ & NS \\
\hline Past use & $8(66)$ & $16(3)$ & $14(17)$ & $16(40)$ & 0.002 \\
\hline \multicolumn{6}{|c|}{ Mycophenolate, \% (n) } \\
\hline Baseline visit & $6(47)$ & $9(6)$ & $13(16)$ & $16(39)$ & $<0.001$ \\
\hline Past use & $6(47)$ & $4(3)$ & $13(16)$ & $22(55)$ & $<0.000$ \\
\hline \multicolumn{6}{|c|}{ Azathioprine, \% (n) } \\
\hline Baseline visit & $20(166)$ & $28(20)$ & $23(28)$ & $27(67)$ & NS \\
\hline Past use & $28(233)$ & $18(13)$ & $42(52)$ & $37(91)$ & $<0.000$ \\
\hline \multicolumn{6}{|c|}{ Methotrexate, \% (n) } \\
\hline Baseline visit & $8(64)$ & $12(9)$ & $6(7)$ & $5(13)$ & NS \\
\hline Past use & $16(131)$ & $4(3)$ & $9(11)$ & $10(24)$ & 0.006 \\
\hline
\end{tabular}

NS: nonsignificant.

compared to Caucasians, Aboriginals, and Afro-Caribbeans $(1.45,1.23$, and 1.63 , respectively; $\mathrm{p}<0.001)$. Univariate associations with damage accumulation are presented in Table 3. As expected, age and disease duration were strongly correlated with damage scores, as was the Charlson Comorbidity Index. Those in the lowest income category had significantly higher SDI scores (1.65 vs 1.03 ; p = 0.002 ), as did those without a high school education (1.90 vs
1.39; $\mathrm{p}=0.004$ ). Renal involvement (as defined by the ACR criteria for renal involvement) was associated with higher damage scores, and both the total number of ACR criteria met and the physicians' global disease activity assessments were correlated with significantly worse damage. While those patients who had ever had a positive Sm antibody had higher damage scores, no other autoantibodies were associated with damage scores (data not shown). Those patients

Table 3. Univariate analyses of associations of clinical and socioeconomic variables with damage.

\begin{tabular}{|c|c|c|c|c|}
\hline \multicolumn{5}{|c|}{ SLICC Damage Index } \\
\hline & With Variable & Without Variable & $\mathrm{r}$ & $\mathrm{p}$ \\
\hline Age & NA & NA & 0.342 & $<0.001$ \\
\hline Disease duration & NA & NA & 0.402 & $<0.001$ \\
\hline Caucasian ethnicity & $1.45 \pm 1.87$ & $1.18 \pm 1.59$ & - & 0.015 \\
\hline Asian ethnicity & $0.95 \pm 1.53$ & $1.47 \pm 1.82$ & - & $<0.001$ \\
\hline Aboriginal ethnicity & $1.23 \pm 1.36$ & $1.36 \pm 1.80$ & - & NS \\
\hline Afro-Caribbean ethnicity & $1.63 \pm 1.74$ & $1.33 \pm 1.78$ & - & NS \\
\hline Annual income $<\$ 15,000$ & $165 \pm 1.87$ & $1.03 \pm 1.55$ & - & 0.002 \\
\hline High school graduate & $1.39 \pm 1.77$ & $1.90 \pm 2.02$ & - & 0.004 \\
\hline Physician global VAS & NA & NA & 0.358 & 0.001 \\
\hline Renal lupus & $1.76 \pm 2.00$ & $1.03 \pm 1.50$ & - & $<0.001$ \\
\hline ACR criteria met & NA & NA & 0.284 & $<0.001$ \\
\hline Anti-Sm antibody & $1.62 \pm 1.74$ & $1.01 \pm 1.50$ & - & $<0.001$ \\
\hline Prednisone, past & $1.55 \pm 1.88$ & $1.09 \pm 1.57$ & - & $<0.001$ \\
\hline Prednisone, current & $1.57 \pm 1.92$ & $1.11 \pm 1.60$ & - & $<0.001$ \\
\hline Antimalarial, current & $1.24 \pm 1.79$ & $1.59 \pm 1.87$ & - & 0.003 \\
\hline Antimalarial, never-use & $1.60 \pm 1.89$ & $1.29 \pm 1.73$ & - & 0.039 \\
\hline Cyclophosphamide, ever & $2.00 \pm 2.16$ & $1.25 \pm 1.70$ & - & $<0.001$ \\
\hline Mycophenolate, ever & $1.71 \pm 1.85$ & $1.28 \pm 1.76$ & - & 0.008 \\
\hline Charlson Comorbidity Index & NA & NA & 0.372 & $<0.001$ \\
\hline
\end{tabular}

NA: not applicable; SLICC: Systemic Lupus International Collaborating Clinics; VAS: visual analog scale; ACR: American College of Rheumatology. NS: nonsignificant. 
currently treated with antimalarials had less damage accumulation, while those who had never been treated with an antimalarial had more. Prednisone, cyclophosphamide, and mycophenolate treatment were all associated with more damage accumulation. Comorbidity, as measured by the Charlson Comorbidity Index, was slightly, but significantly higher in Aboriginals compared to the other 3 groups ( $\mathrm{p}=$ 0.05; Table 1).

In multivariate analysis (Table 4), the most important variables in the model to predict damage were disease duration, age, SLAM-R, current prednisone treatment, the use of cyclophosphamide (ever), and low income, with an $\mathrm{R}^{2}$ for the model of 0.27 . It is likely that cyclophosphamide and prednisone treatment in this analysis reflect greater disease severity as much as or more than a causal association between treatment and damage, given that this is a prevalent cohort where past treatment patterns and timing of damage accrual are not known. Of note, ethnicity, renal involvement, autoantibodies, education, and antimalarial use were not retained in the model.

\section{DISCUSSION}

The 1000 Canadian Faces of Lupus study illustrates the marked ethnic diversity of the Canadian lupus population. In our study we have clearly demonstrated ethnic differences in disease expression and therapy, despite a universal healthcare system.

Almost $40 \%$ of those in our cohort reported non-Caucasian ethnicity, which is higher than the proportion of visible minority and Aboriginal people in the general population of Canada (17\% in 2001) $)^{27,40}$. It is not clear whether this reflects a greater predisposition to lupus in non-Caucasians, or the demography of large Canadian urban centers where most of the participating clinics are located. The distribution of visible minority peoples varies widely across Canadian provinces and cities; the majority of Asian and Afro-Caribbean Canadians live in or near larger urban centers ${ }^{40}$. The reverse is true for Canadian Aboriginals: only $27 \%$ of Aboriginals live in larger metropolitan areas, the remainder live on reservations, rural areas, or communities $^{41}$. At $5 \%$, the proportion of Aboriginals in our cohort was only slightly higher than that of Aboriginals in the general Canadian population at 3\%. Health utilization patterns of Aboriginal people may also play a role; lower rates of specialist contact have been documented for Aboriginal people, in spite of lower health indicators ${ }^{42,43}$. Visible minority and Aboriginal Canadians are projected to increase to $25 \%$ of the population by $2017^{28,41}$; therefore, although our cohort is clearly not population-based it does indicate the need for further study of the influence of ethnicity on disease expression among patients with lupus in Canada.

Asian and Afro-Caribbean patients with lupus in this cohort had evidence of similarly severe disease, with a high frequency of lupus nephritis, and frequent treatment with corticosteroids, cyclophosphamide, and mycophenolate. However, at an average of 10 years of disease, almost $60 \%$ of Asians had no damage accumulation, compared to only $35 \%$ of Afro-Caribbean patients with lupus, who also had higher mean SDI scores. Previous studies have reported greater damage accrual in Afro-Caribbean patients, but there are few reports in Asians. In another Canadian study of a multiethnic cohort followed at a single center, Asians had more damage accrual than African-Canadians with similar disease duration and ages ${ }^{44}$. As described by others, we found that older age was an important predictor for damage accumulation in our cohort ${ }^{25,45,46}$. Socioeconomic status (household income and education) in Asians in this cohort was on par with Caucasians, while household income was lower for Afro-Caribbeans. While there are no data on Asian patients with lupus, it is likely that higher socioeconomic status had an important protective effect on damage accumulation for Asians in this cohort, as has been shown in studies of other ethnic groups ${ }^{20,26,47}$.

Lupus in Aboriginal Canadians in this study was less severe than previously described ${ }^{11-13}$, essentially very similar to the Caucasian group. The main differences were higher comorbidity scores in spite of shorter disease duration, and significantly lower levels of education and household

Table 4. Multivariate analysis of association of clinical and sociodemographic factors with damage accumulation.

\begin{tabular}{lcccc}
\hline Independent Variable & $\begin{array}{c}\text { Measure } \\
\text { Estimate }\end{array}$ & $\begin{array}{c}\text { Standard } \\
\text { Error }\end{array}$ & $95 \%$ CI for $\beta$ & $\mathrm{p}$ \\
\hline Disease duration & 0.057 & 0.008 & $0.042-0.072$ & $<0.001$ \\
Age & 0.017 & 0.004 & $0.009--0.025$ & $<0.001$ \\
Low income & -0.154 & 0.057 & $-0.267--0.041$ & 0.007 \\
Disease activity (SLAM-R) & 0.049 & 0.015 & $0.018-0.079$ & 0.002 \\
Cyclophosphamide treatment (ever) & 0.667 & 0.184 & $0.305-1.084$ & $<0.001$ \\
Prednisone treatment (at baseline visit) & 0.284 & 0.129 & $0.029-0.538$ & 0.029 \\
\hline
\end{tabular}

* All the analyses were done using stepwise, forward, and backward linear regression analyses, with identical results. Variables excluded from the final model were ethnicity, high school completion, total ACR criteria met, physician global VAS, anti-Sm antibody, renal lupus, antimalarial treatment, and mycophenolate treatment. SLAM-R: revised Systemic Lupus Activity Measure. 
income. Onset age was also not different from that of the Caucasians, again different from previous reports, which describe a younger onset age. This may relate to the methods, as the previous reports were population-based, while our study is based on those patients presenting for care to lupus clinics, and agreeing to participate in the study. Alternatively, it is also very possible that due to the long disease duration of the cohort ( $7 \mathrm{yrs}$ for Aboriginals, $12 \mathrm{yrs}$ overall), those Aboriginal patients with the most severe disease did not survive to become part of the cohort (survivor bias), thus underestimating disease severity for the group as a whole. Such a survival bias may also underestimate disease severity for the entire cohort.

Aboriginal Canadians in this cohort also had a strikingly high prevalence of aPL, a previously unreported finding. The significance and implications of this finding are not clear. There is a well described association between aPL and infections ${ }^{48-50}$, and rates of many infections are more common in Aboriginals, including hepatitis $\mathrm{C}$, otitis media, gastroenteritis, and tuberculosis ${ }^{51-54}$. We do not have data on infectious exposures in this cohort. Rates of venous thrombotic events were not higher in this group (data not shown), but atherosclerotic events (myocardial infarctions and cerebrovascular accidents) as collected in the SLICC Damage Index and the Charlson Comorbidity Index were highest in Aboriginals, at 20\%, compared to $11 \%$ in Caucasians, $7 \%$ in Afro-Caribbeans, and 5\% in Asians $(\mathrm{p}=0.002)$. However, smoking rates and prevalence of diabetes were also highest in Aboriginal patients (data not shown). The relative importance of aPL in Aboriginal patients with lupus is an important area of future research.

Low household income was one of the strongest predictors of damage accrual in this cohort, in spite of supposed equal access to healthcare. Some previous studies ${ }^{47,55,56}$, but not all ${ }^{22}$, have found low income or low socioeconomic status to be a predictor of damage and poor outcomes. Low income and mortality in lupus are more clearly linked ${ }^{57,58}$. There is an extensive body of literature showing overall socioeconomic status to vary inversely with outcomes in chronic disease in general ${ }^{59-61}$. The persistence and strength of this variable in the setting of public healthcare support the complex interaction between socioeconomic status and health-related behaviors.

A number of limitations are recognized in our study. Concerns include the definition of the ethnic groups. While we report ethnic groups in 4 large categories, clearly there are differences to be found within these groups. Further, the effect of mixed parental heritage and heterogeneous backgrounds was not taken into account by these methods. Data on detailed ethnic origin are collected and will be the subject of future analyses. Genetic admixture analysis would be a valuable tool to better account for mixed ethnic heritage and determine the genetic component of ethnicity and its contribution to disease course and outcome, as has been shown successfully in other studies ${ }^{62,63}$. We are in the process of collecting DNA, and hope to do this in the future.

As this is largely a prevalent rather than an incident cohort, patterns of past disease activity are not known, past clinical manifestations may have been missed, and treatment burden underestimated. As mentioned, those with the most severe disease may be less likely to survive for inclusion in the cohort, making differences between ethnic groups less evident and limiting conclusions about the disease course.

We have shown there are differences in lupus phenotypes between ethnic groups when examining age of onset, clinical manifestations, and autoantibody profiles. Further, although we did not demonstrate ethnicity to independently predict accumulation of damage, we did find that low income remains a very strong independent predictor of damage accrual, despite a setting of universal healthcare. It may well be that genetic factors are most important in determining disease activity and clinical manifestations, but that socioeconomic factors are more important in determining longterm outcomes.

\section{ACKNOWLEDGMENT}

We thank the CaNIOS coordinators and research assistants for their dedicated work in recruiting the patients: Andrea Craig, 1000 Faces National Coordinator, University of Manitoba; Jaime Claudio, PhD, CaNIOS National Coordinator, University Health Network; Sara Hewitt and Janine Ouimet, St. Joseph's Health Centre, London, Ontario; Mellissa Moyen, Health Sciences Center, Winnipeg; Michele Tobaly and Tania Santopietro, Montreal General Hospital; Diane Ferland, Hopital MaisonneuveRosemont, Montreal; Sherri Simpson and Katrin Smith, Ottawa Hospital; Tony Hong, America Uribe, and Meghan MacLeod, Vancouver General Hospital; Annella Wehlage, Lethbridge, Alberta; Jessica Bernstein, Jewish General Hospital; Tamara McKenzie, University Health Network.

Canadian Network for Improved Outcomes in Systemic Lupus Erythematosus (CaNIOS) 1000 Faces Investigators: Glinda S. Cooper, PhD, Environmental Protection Agency, Washington, DC, USA; Lori Albert, MD, S. Carette, MPhil, MD, and R.D. Inman, BA, MD, Toronto Western Hospital, University Health Network, Department of Medicine, University of Toronto, Toronto, Ontario; Carol Hitchon, MD, MSc, Health Sciences Centre, University of Manitoba, Winnipeg, Manitoba; Lori Tucker, MD, and Ross Petty, MD, Vancouver Children's Hospital, University of British Columbia, Vancouver, BC; Gaelle Chedéville, MD, Sarah Campillo, MD, Karen Duffy, MD, and Rosie Scuccimarri, MD, Montreal Children's Hospital; Murray Baron, MD, and Laeora Berkson, MD, Jewish General Hospital, McGill University, Montreal, Quebec; Suzanne Ramsey, MD, and Adam Huber, MD, IWK Grace Health Centre, Dalhousie University, Halifax, Nova Scotia, Canada.

\section{REFERENCES}

1. Siegel M, Lee SL. The epidemiology of systemic lupus erythematosus. Semin Arthritis Rheum 1973;3:1-54.

2. McCarty DJ, Manzi S, Medsger TA Jr, Ramsey-Goldman R, LaPorte RE, Kwoh CK. Incidence of systemic lupus erythematosus. Race and gender differences. Arthritis Rheum 1995;38:1260-70.

3. Lawrence RC, Hochberg MC, Kelsey JL, et al. Estimates of the prevalence of selected arthritic and musculoskeletal diseases in the United States. J Rheumatol 1989;16:427-41.

4. Kaslow RA, Masi AT. Age, sex, and race effects on mortality from systemic lupus erythematosus in the United States. Arthritis Rheum 1978;21:473-9. 
5. Hopkinson ND, Doherty M, Powell RJ. Clinical features and race-specific incidence/prevalence rates of systemic lupus erythematosus in a geographically complete cohort of patients. Ann Rheum Dis 1994;53:675-80.

6. Hochberg MC. The incidence of systemic lupus erythematosus in Baltimore, Maryland, 1970-1977. Arthritis Rheum 1985;28:80-6.

7. Fessel WJ. Systemic lupus erythematosus in the community. Incidence, prevalence, outcome, and first symptoms; the high prevalence in black women. Arch Intern Med 1974;134:1027-35.

8. Samanta A, Feehally J, Roy S, Nichol FE, Sheldon PJ, Walls J. High prevalence of systemic disease and mortality in Asian subjects with systemic lupus erythematosus. Ann Rheum Dis 1991;50:490-2.

9. Samanta A, Roy S, Feehally J, Symmons DP. The prevalence of diagnosed systemic lupus erythematosus in whites and Indian Asian immigrants in Leicester city, UK. Br J Rheumatol 1992;31:679-82.

10. Johnson AE, Gordon C, Palmer RG, Bacon PA. The prevalence and incidence of systemic lupus erythematosus in Birmingham, England. Relationship to ethnicity and country of birth. Arthritis Rheum 1995;38:551-8.

11. Boyer GS, Templin DW, Lanier AP. Rheumatic diseases in Alaskan Indians of the southeast coast: high prevalence of rheumatoid arthritis and systemic lupus erythematosus. J Rheumatol 1991;18:1477-84.

12. Hitchon CA, Peschken CA. Sm antibodies increase risk of death in systemic lupus erythematosus. Lupus 2007;16:186-94.

13. Peschken CA, Esdaile JM. Systemic lupus erythematosus in North American Indians: a population based study. J Rheumatol 2000;27:1884-91.

14. Alarcon GS, Roseman J, Bartolucci AA, et al. Systemic lupus erythematosus in three ethnic groups: II. Features predictive of disease activity early in its course. LUMINA Study Group. Lupus in minority populations, nature versus nurture. Arthritis Rheum 1998;41:1173-80.

15. Kaslow RA. High rate of death caused by systemic lupus erythematosus among U.S. residents of Asian descent. Arthritis Rheum 1982;25:414-8.

16. Lau CS, Yin G, Mok MY. Ethnic and geographical differences in systemic lupus erythematosus: an overview. Lupus 2006;15:715-9.

17. Molina JF, Molina J, Garcia C, Gharavi AE, Wilson WA, Espinoza LR. Ethnic differences in the clinical expression of systemic lupus erythematosus: a comparative study between African-Americans and Latin Americans. Lupus 1997;6:63-7.

18. Quintero-Del-Rio AI, Bacino D, Kelly J, Aberle T, Harley JB. Familial systemic lupus erythematosus: a comparison of clinical manifestations and antibody presentation in three ethnic groups. Cell Mol Biol (Noisy-le-grand) 2001;47:1223-7.

19. Alarcon GS, Friedman AW, Straaton KV, et al. Systemic lupus erythematosus in three ethnic groups: III. A comparison of characteristics early in the natural history of the LUMINA cohort. LUpus in MInority populations: NAture vs. Nurture. Lupus 1999;8:197-209.

20. Alarcon GS, McGwin G Jr, Bartolucci AA, et al. Systemic lupus erythematosus in three ethnic groups. IX. Differences in damage accrual. Arthritis Rheum 2001;44:2797-806.

21. Alarcon GS, McGwin G Jr, Petri M, et al. Time to renal disease and end-stage renal disease in PROFILE: a multiethnic lupus cohort. PLoS Med 2006;3:e396.

22. Rivest C, Lew RA, Welsing PM, et al. Association between clinical factors, socioeconomic status, and organ damage in recent onset systemic lupus erythematosus. J Rheumatol 2000;27:680-4.

23. Uribe AG, McGwin G Jr, Reveille JD, Alarcon GS. What have we learned from a 10-year experience with the LUMINA (Lupus in Minorities; Nature vs. nurture) cohort? Where are we heading? Autoimmun Rev 2004;3:321-9.
24. Karlson EW, Daltroy LH, Lew RA, et al. The independence and stability of socioeconomic predictors of morbidity in systemic lupus erythematosus. Arthritis Rheum 1995;38:267-73.

25. Karlson EW, Daltroy LH, Lew RA, et al. The relationship of socioeconomic status, race, and modifiable risk factors to outcomes in patients with systemic lupus erythematosus. Arthritis Rheum 1997;40:47-56.

26. Ward MM, Pyun E, Studenski S. Long-term survival in systemic lupus erythematosus. Patient characteristics associated with poorer outcomes. Arthritis Rheum 1995;38:274-83.

27. Projections of the Aboriginal Populations, Canada, Provinces and Territories; 2001-2017. Minister of Industry, Government of Canada; 2005 Jun 1. Report No.: Catalogue no. 91-547-XIE.

28. Belanger A, Malenfant C. Population projections of visible minority groups, Canada, provinces and regions; 2001-2017. Minister of Industry, Government of Canada; 2005 May 1. Report No.: Catalogue No. 91-541-XIE.

29. Hochberg MC. Updating the American College of Rheumatology revised criteria for the classification of systemic lupus erythematosus. Arthritis Rheum 1997;40:1725.

30. Liang MH, Socher SA, Larson MG, Schur PH. Reliability and validity of six systems for the clinical assessment of disease activity in systemic lupus erythematosus. Arthritis Rheum 1989;32:1107-18.

31. Bae SC, Koh HK, Chang DK, Kim MH, Park JK, Kim SY. Reliability and validity of Systemic Lupus Activity Measure-revised (SLAM-R) for measuring clinical disease activity in systemic lupus erythematosus. Lupus 2001;10:405-9.

32. Bombardier C, Gladman DD, Urowitz MB, Caron D, Chang CH. Derivation of the SLEDAI. A disease activity index for lupus patients. The Committee on Prognosis Studies in SLE. Arthritis Rheum 1992;35:630-40.

33. Gladman DD, Ibanez D, Urowitz MB. Systemic Lupus Erythematosus Disease Activity Index 2000. J Rheumatol 2002;29:288-91.

34. Karlson EW, Daltroy LH, Rivest C, et al. Validation of a Systemic Lupus Activity Questionnaire (SLAQ) for population studies. Lupus 2003;12:280-6

35. Ware JE Jr, Sherbourne CD. The MOS 36-item Short-form Health Survey (SF-36). I. Conceptual framework and item selection. Med Care 1992;30:473-83.

36. Gladman D, Ginzler E, Goldsmith C, et al. The development and initial validation of the Systemic Lupus International Collaborating Clinics/American College of Rheumatology damage index for systemic lupus erythematosus. Arthritis Rheum 1996;39:363-9.

37. Gladman DD, Urowitz MB, Goldsmith $\mathrm{CH}$, et al. The reliability of the Systemic Lupus International Collaborating Clinics/American College of Rheumatology Damage Index in patients with systemic lupus erythematosus. Arthritis Rheum 1997;40:809-13.

38. Charlson ME, Pompei P, Ales KL, MacKenzie CR. A new method of classifying prognostic comorbidity in longitudinal studies: development and validation. J Chronic Dis 1987;40:373-83.

39. 2001 Census dictionary — Internet version. [92-378-XIE]. 3-12-2002. Statistics Canada.

40. Statistics Canada. Visible minority population, by province and territory (2001 Census) (Table); Canadian Statistics. Last updated January 25, 2005. [Internet. Accessed March 27, 2009.] Available from: http://www40.statcan.gc.ca/101/cst01/demo52a-eng.htm

41. Michalowski M, Loh S, Verma R, Germain M, Grenier C. Projections of the Aboriginal populations, Canada, provinces and territories. Statistics Canada; 2005 Jun 28. Report No.: Catalogue no. 91-547-XIE.

42. Martens PJ, Sanderson D, Jebamani L. Health services use of Manitoba First Nations people: is it related to underlying need? Can J Public Health 2005;96 Suppl:S39-44. 
43. Newbold KB. Problems in search of solutions: health and Canadian aboriginals. J Community Health 1998;23:59-73.

44. Johnson SR, Urowitz MB, Ibanez D, Gladman DD. Ethnic variation in disease patterns and health outcomes in systemic lupus erythematosus. J Rheumatol 2006;33:1990-5.

45. Sung YK, Hur NW, Sinskey JL, Park D, Bae SC. Assessment of damage in Korean patients with systemic lupus erythematosus. J Rheumatol 2007;34:987-91.

46. Yee CS, Hussein H, Skan J, Bowman S, Situnayake D, Gordon C. Association of damage with autoantibody profile, age, race, sex and disease duration in systemic lupus erythematosus. Rheumatology 2003;42:276-9.

47. Cooper GS, Treadwell EL, St. Clair EW, Gilkeson GS, Dooley MA. Sociodemographic associations with early disease damage in patients with systemic lupus erythematosus. Arthritis Rheum 2007;57:993-9.

48. Avcin T, Toplak N. Antiphospholipid antibodies in response to infection. Curr Rheumatol Rep 2007;9:212-8.

49. Habibagahi Z, Nazarinia MA, Aflaki E, Rajaee A. Anticardiolipin and anti-beta-2-glycoprotein I antibodies in patients with hepatitis B and C infections. Iran J Immunol 2007;4:161-6.

50. von Landenberg P, Doring Y, Modrow S, Lackner KJ. Are antiphospholipid antibodies an essential requirement for an effective immune response to infections? Ann NY Acad Sci 2007;1108:578-83.

51. Hoeppner VH, Marciniuk DD. Tuberculosis in aboriginal Canadians. Can Respir J 2000;7:141-6.

52. MacMillan HL, MacMillan AB, Offord DR, Dingle JL. Aboriginal health. CMAJ 1996;155:1569-78.

53. McConnell A, Tan B, Scheifele D, et al. Invasive infections caused by haemophilus influenzae serotypes in twelve Canadian IMPACT centers, 1996-2001. Pediatr Infect Dis J 2007;26:1025-31.
54. Wu HX, Wu J, Wong T, et al. Incidence and risk factors for newly acquired hepatitis $\mathrm{C}$ virus infection among Aboriginal versus non-Aboriginal Canadians in six regions, 1999-2004. Eur J Clin Microbiol Infect Dis 2007;26:167-74.

55. Sutcliffe N, Clarke AE, Levinton C, Frost C, Gordon C, Isenberg DA. Associates of health status in patients with systemic lupus erythematosus. J Rheumatol 1999;26:2352-6.

56. Lotstein DS, Ward MM, Bush TM, Lambert RE, van Vollenhoven R, Neuwelt CM. Socioeconomic status and health in women with systemic lupus erythematosus. J Rheumatol 1998;25:1720-9.

57. Uribe AG, Alarcon GS. Ethnic disparities in patients with systemic lupus erythematosus. Curr Rheumatol Rep 2003;5:364-9.

58. Walsh SJ, DeChello LM. Geographical variation in mortality from systemic lupus erythematosus in the United States. Lupus 2001;10:637-46.

59. Broom DH. The social distribution of illness: is Australia more equal? Soc Sci Med 1984;18:909-17.

60. Duran S, Apte M, Alarcon GS. Poverty, not ethnicity, accounts for the differential mortality rates among lupus patients of various ethnic groups. J Natl Med Assoc 2007;99:1196-8.

61. Hay DI. Socioeconomic status and health status: a study of males in the Canada Health Survey. Soc Sci Med 1988;27:1317-25.

62. Alarcon GS, Bastian HM, Beasley TM, et al. Systemic lupus erythematosus in a multi-ethnic cohort (LUMINA) XXXII: [corrected] contributions of admixture and socioeconomic status to renal involvement. Lupus 2006;15:26-31.

63. Alarcon GS, Beasley TM, Roseman JM, et al. Ethnic disparities in health and disease: the need to account for ancestral admixture when estimating the genetic contribution to both (LUMINA XXVI) Lupus 2005; 14:867-8. 